\title{
Screening and Identification of Sources of Salinity Tolerance at Seed Germination Stage in Indian Soybean Genotypes
}

\author{
Shanti Kumari ${ }^{*}$, S K. Lal ${ }^{1}$, V. Sreenivasa ${ }^{1}$, Ambika Rajendran ${ }^{1}$, \\ Sunil Kumar Singh ${ }^{1}$, KP. Singh ${ }^{1}$, S.K. Jain ${ }^{2}$ and D. Xu ${ }^{3}$ \\ ${ }^{1}$ Genetics Division, Indian Agricultural Research Institute, New Delhi, India \\ ${ }^{2}$ Division of Seed Science and Technology, Indian Agricultural Research Institute, \\ New Delhi, India \\ ${ }^{3}$ Japan International Research Centre for Agricultural Science (JIRCAS), \\ Ohwashi, Tsukuba, Ibaraki 305-8686, Japan \\ *Corresponding author
}

\section{A B S T R A C T}

\begin{tabular}{|c|}
\hline Keywords \\
\hline $\begin{array}{l}\text { Salinity tolerance, } \\
\text { Seed germination, } \\
\text { Soybean, Glycine } \\
\max \text { (L.) Merrill }\end{array}$ \\
\hline Article Info \\
\hline $\begin{array}{l}\text { Accepted: } \\
20 \text { March } 2019 \\
\text { Available Online: } \\
10 \text { April } 2019\end{array}$ \\
\hline
\end{tabular}

\begin{abstract}
Salinity has negative impact on plants such as poor germination, reduction in root length, reduction in shoot length and adverse effect on early seedling growth. In order to study the effect of salinity $(\mathrm{NaCl} 180 \mathrm{mM})$ on seed germination of soybean, an experiment was conducted to screen 82 diverse soybean genotypes. The results revealed that salinity stress caused by $\mathrm{NaCl}$ reduced both germination percentage and seedling growth of soybean varieties. Genotypes differed significantly in terms of tolerance to salinity. Mean seed germination of the 82 soybean genotypes under normal condition was $90.69 \%$ whereas the mean seed germination under salt stress was $8.82 \%$. Out of 82 lines screened at $180 \mathrm{mM}$ $\mathrm{NaCl}$, sixty six genotypes failed to germinate ( $0 \%$ germination). Only sixteen genotypes showed germination. The seed germination among these sixteen genotypes varied from 3.33 per cent to 100per cent. Three genotypes Pusa 9712, PS-1572 and FT-ABYARA exhibited 100\% seed germination. Whereas genotypes E-20, JS-20-19 and Bragg showed $73.33 \%, 63.33 \%$ and $80 \%$ seed germination respectively under salt stress.
\end{abstract}

\section{Introduction}

Soybean is a moderately salt-sensitive crop (Munns and Tester, 2008). Salinity has adverse effect on plant growth because it causes osmotic stress, interrupts metabolic processes and uptake of macro and micro nutrients (Paternak, 1987). These adverse effects of salinity affects seed germination, plant growth (Wang \& Shannon, 1999) and nodule formation (Singleton and Bohlool, 1984). A number of studies have been conducted to identify salt tolerance at seedling stage in soybean (Do et al, 2016). But there are few reports on salt tolerance at seed germination stage in soybean. The study of stage-specific variability in response to stress will help in identification of heritable components of salt tolerance (Fooland and Jones, 1991). To improve the salinity 
tolerance of the soybean cultivars it is imperative to combine tolerance at seed germination stage with tolerance at seedling stage. Therefore, a random set of 82 diverse genotypes were screened for seed germination to identify the sources of salinity tolerance at seed germination stage.

\section{Materials and Methods}

\section{Experimental material}

The experimental material consisted of 82diverse soybean germplasm lines (Table 1) selected randomly from Germplasm Collection of Soybean Improvement Project at Genetics Division, IARI, Pusa Campus, New Delhi. The data on morphological characters of these 82 genotypes are summarized in table 2 . The mean and range indicates that they are quite diverse.

Screening for salt tolerance at seed germination stage

Experiment was performed in completely randomized design (CRD) with three replicates of 60 seeds each. Surface sterilization of healthy and uniform seed was done with $0.2 \% \mathrm{HgCl}_{2}$ for 1 minutes followed by 3-4 time washes with the distilled water. Saline solution $(180 \mathrm{mM}) \mathrm{NaCl}$ concentration was prepared and $10 \mathrm{ml}$ of this saline solution was used. Experiment was conducted in sterilized Petri-dishes containing filter paper circles, covered over by aluminium foil and autoclaved at $121^{\circ} \mathrm{C}$ for 15 minutes. Seeds were allowed to germinate in dark room at 27 ${ }^{\circ} \mathrm{C}$. In control sample, $10 \mathrm{ml}$ of distilled water was used. In Control sample, $10 \mathrm{ml}$ of distilled water was used. Observations were carried out from 3 to 6 DAS. On the $7^{\text {th }}$ day of germination plant part of seedlings were separated and data recorded on shoot and root length (in $\mathrm{cm}$ ), hard seed, dead, normal and abnormal seed. Counts of germinated seeds were made each day, and then a final germination percentage (FGP) computed by using the formula:

Final Germination Percentage $(\%)=$ No. of germinated seed / Total No. of seed X 100.

\section{Results and Discussion}

\section{Standardisation of $\mathrm{NaCl}$ concentration}

To determine the most suitable salt concentration a random set of 36 genotypes were selected and these lines were screened for seed germination at three different concentrations $(180 \mathrm{mM}, 200 \mathrm{mM}$ and $250 \mathrm{mM} \mathrm{NaCl}$ ). The data is summarized in Figure 1 and 2. More genetic variation for tolerance to salinity at germination stage was observed at $180 \mathrm{mM} \mathrm{NaCl}$ than in the other two treatments. At $200 \mathrm{mM}$ and $250 \mathrm{mM}$ all the genotypes failed to germinate except one genotype (Pusa 9712).Therefore, the accessions were evaluated for tolerance to salinity at seed germination stage at $180 \mathrm{mM}$ $\mathrm{NaCl}$. Eighty two diverse genotypes were screened for tolerance to salinity $(180 \mathrm{mM}$ $\mathrm{NaCl}$ ) at seed germination stage (Table 1). Analysis of variance showed that these genotypes differed significantly for germination percentage under stress as well as for root length and shoot length (Table 3 ).

\section{Effect of salton seed germination}

Mean seed germination of the 82 soybean genotypes screened was 90.69 per cent whereas the mean seed germination under salt stress was 8.82 per cent (Table 2). Out of 82 lines screened at $180 \mathrm{mM} \mathrm{NaCl}$, sixty six genotypes failed to germinate (Figure 3). Only sixteen genotypes showed germination. The seed germination among these sixteen genotypes varied from $3.33 \%$ to $100 \%$ (Figure 4). Three genotypes Pusa 9712 (Fig. 4), PS-1572 and FT-ABYARA exhibited 
$100 \%$ seed germination. Whereas E-20, JS20-19 and Bragg showed 73.33\%, 63.33\% and $80 \%$ seed germination respectively under salt stress.

\section{Reduction in root length and shoot length}

The mean root averaged over all genotypes decreased from $7.04 \mathrm{~cm}$ (control) to $0.51 \mathrm{~cm}$ (stress) and mean shoot length decreased from $10.59 \mathrm{~cm}$ (control) to $2.84 \mathrm{~cm}$ (stress) (Table 2). The reduction of growth is a common phenomenon of many crop plants grown under saline conditions and our findings are in line with earlier reports (Maliwal and Paliwal, 1982; Hosseini et al, 2002 and Hakim et al, 2010). This result is in agreement with Agarwal et al, (2015); they reported that salinity reduced shoot length. Negative impact of salinity might be because of ions toxic effects and inhibition of water uptake by potential osmotic changes so disturbed metabolism for growth (Dolatabadian et al, 2011).

Sixty six genotypes out of eighty two genotypes failed to germinate. Only five genotypes exhibited more than $60 \%$ germination (Figure 3). There was no loss of germination in three out of five lines (Figure 4 and 5). In these three genotypes reduction in root length was more as compared to reduction in shoot length (Figure 5). Pusa 9712 recorded least reduction in root length whereas FT-ABYARA recoded least reduction in shoot length as compared to the control.

Table.1 List of genotypes of Glycine max L. Merrill used for seed germination screening

\begin{tabular}{|c|l|l|l|l|l|l|l|}
\hline SN & \multicolumn{1}{|c|}{ Genotype } & SN & \multicolumn{1}{|c|}{ Genotype } & \multicolumn{1}{|c|}{ SN } & \multicolumn{1}{|c|}{ Genotype } & SN & \multicolumn{1}{|c|}{ Genotype } \\
\hline $\mathbf{1}$ & PS-1506 & 23 & EC-457274 & 45 & EC-47229 & 66 & PK-1024 \\
\hline $\mathbf{2}$ & AMS-56 & 24 & DSB-19 & 46 & EC-472242 & 67 & DS-9812 \\
\hline $\mathbf{3}$ & E-20 & 25 & VLS-61 & 47 & EC-457415 & 68 & EC-45741 \\
\hline $\mathbf{4}$ & JS-20-19 & 26 & DS-76-1-2-1 & 48 & DS-9909 & 69 & TS-148-22 \\
\hline $\mathbf{5}$ & DS-9820 & 27 & MACS-480 & 49 & MACS-231 & 70 & G-2132 \\
\hline $\mathbf{6}$ & NRC-89 & 28 & MACS-869 & 50 & DS-2001 & 71 & G-2144 \\
\hline $\mathbf{7}$ & VLS-74 & 29 & DS-2006 & 51 & DS-2004 & 72 & G-2215 \\
\hline $\mathbf{8}$ & PS-1466 & 30 & PK-1169 & 52 & DS-2005 & 73 & EC-389179 \\
\hline $\mathbf{9}$ & TS-1450 & 31 & PK-1243 & 53 & HIMS0-1563 & 74 & USSL-291 \\
\hline $\mathbf{1 0}$ & RKS-115 & 32 & PK-1135 & 54 & HIS-01 & 75 & EC-458383 \\
\hline $\mathbf{1 1}$ & DS-12-13 & 33 & SL-46 & 55 & LEE & 76 & EC-456615 \\
\hline $\mathbf{1 2}$ & PS-1503 & 34 & L-1169 & 56 & KB-222 & 77 & EC-457398 \\
\hline $\mathbf{1 3}$ & DS-2708 & 35 & L-1180 & 57 & TS-3 & 78 & PS-1480 \\
\hline $\mathbf{1 4}$ & BRAGG & 36 & UPSL-289 & 58 & UGM-20075 & 79 & SS-222 \\
\hline $\mathbf{1 5}$ & MACS-450 & 37 & TGX1835-3E & 59 & DS-9817 & 80 & PS-1572 \\
\hline $\mathbf{1 6}$ & MACS-1336 & 38 & EC-472184 & 60 & PK-1024 & 81 & PUSA-16 \\
\hline $\mathbf{1 7}$ & DS-2614 & 39 & PK-1060 & 61 & DS-9816 & 82 & FT-Abayra \\
\hline $\mathbf{1 8}$ & PS-1477 & 40 & MAUS- 81 & 62 & JS-20-05 & & \\
\hline $\mathbf{1 9}$ & PUSA- 9712 & 41 & PK-1041 & 63 & SH-14 & & \\
\hline $\mathbf{2 0}$ & PS 1347 & 42 & NRC-53 & 64 & UPSV-22 & & \\
\hline $\mathbf{2 1}$ & SL 688 & 43 & MAUS-666 & 65 & SL-958 & & \\
\hline $\mathbf{2 2}$ & SL 979 & 44 & VLS-57 & 66 & EC-391158 & & \\
\hline & & & & & & & \\
\hline
\end{tabular}


Table.2 Descriptive statistics for quantitative characters of genotypes screened for salt tolerance

\begin{tabular}{|l|l|l|l|l|l|l|}
\hline Characters & Minimum & Maximum & Range & Mean & SE (d) & CV\% \\
\hline $\begin{array}{l}\text { Days to 50\% } \\
\text { flowering }\end{array}$ & 34.16 & 65.16 & 31.0 & 49.98 & 3.53 & 7.0 \\
\hline Days to maturity & 93.7 & 125.3 & 31.6 & 109.5 & 11.0 & 10.0 \\
\hline Plant Height & 50.13 & 101.53 & 51.4 & 72.80 & 11.7 & 16.0 \\
\hline Branches/plant & 2.0 & 11.0 & 9.0 & 5.29 & 0.85 & 16.0 \\
\hline $\begin{array}{l}\text { No. of pods per } \\
\text { plant }\end{array}$ & 14.41 & 95.99 & 81.6 & 38.52 & 1.41 & 3.66 \\
\hline 100-seed weight & 6.72 & 13.84 & 7.11 & 10.77 & 1.36 & 12.62 \\
\hline Seed yield/ row & 14.96 & 514.98 & 501.95 & 117.17 & 43.2 & 26.86 \\
\hline
\end{tabular}

Table.3 Analysis of variance for seed germination, root length and shoot length under normal and stress condition

\begin{tabular}{|c|c|c|c|c|c|c|}
\hline & \multicolumn{2}{|c|}{ Seed germination (\%) } & \multicolumn{2}{c|}{ Root length (cm) } & \multicolumn{2}{c|}{ Shoot length (cm) } \\
\hline & Control & Stress & Control & Stress & Control & Stress \\
\hline Mean & 90.691 & 8.821 & 7.043 & 0.513 & 10.59 & 2.84 \\
\hline CV\% & 12.034 & 72.997 & 16.536 & 65.986 & 11.139 & 89.633 \\
\hline F Prob. & 0.000 & 0.000 & 0.000 & 0.000 & 0.000 & 0.000 \\
\hline SEM & 6.301 & 3.718 & 0.672 & 0.196 & 0.599 & 0.147 \\
\hline $\begin{array}{c}\text { CD at } \\
\text { 5\% }\end{array}$ & 17.595 & 10.381 & 1.878 & 0.546 & 1.673 & 0.411 \\
\hline $\begin{array}{c}\text { CD at } \\
\mathbf{1 \%}\end{array}$ & 23.223 & 13.702 & 2.478 & 0.721 & 2.209 & 0.542 \\
\hline
\end{tabular}

Fig.1 Frequency distribution of 36 genotypes for seed germination in control and at $180 \mathrm{mM}$ $\mathrm{NaCl}$

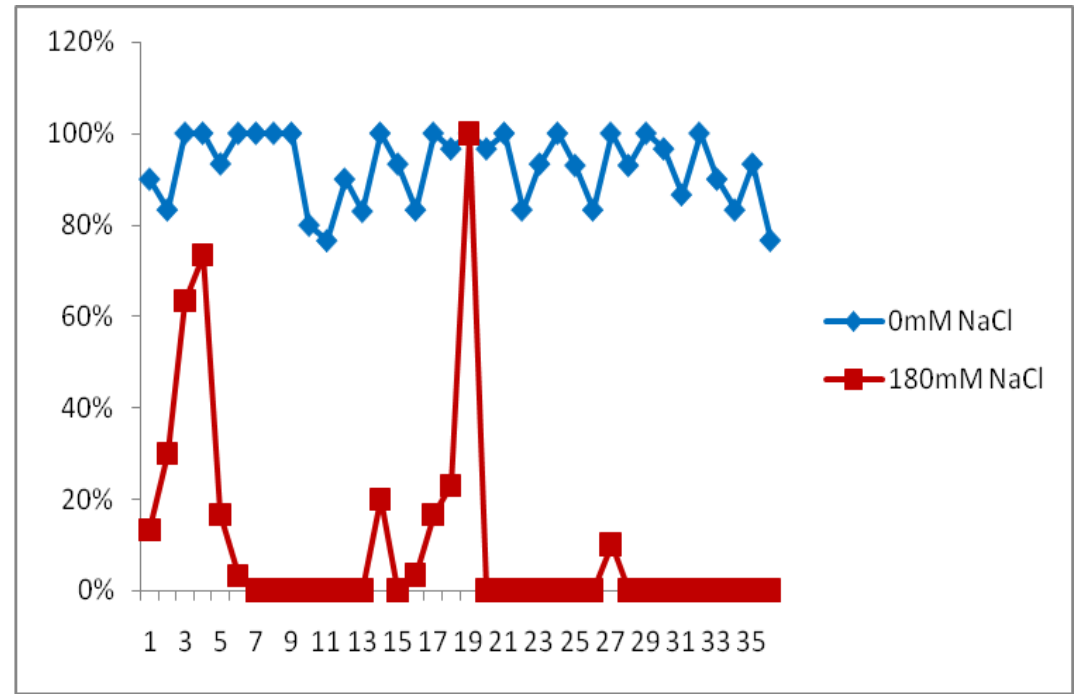


Fig.2 Frequency distribution of 36 genotypes for seed germination at 200 and $250 \mathrm{mM} \mathrm{NaCl}$

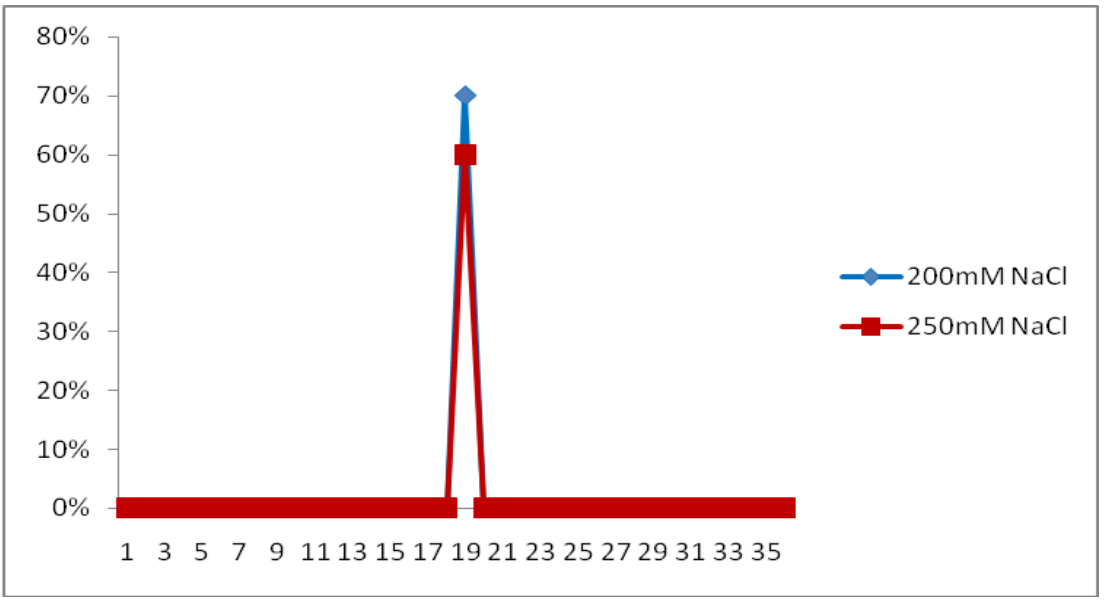

Fig.3 Frequency distribution of eighty two genotypes for per cent germination under salinity stress $(180 \mathrm{mM} \mathrm{NaCl})$

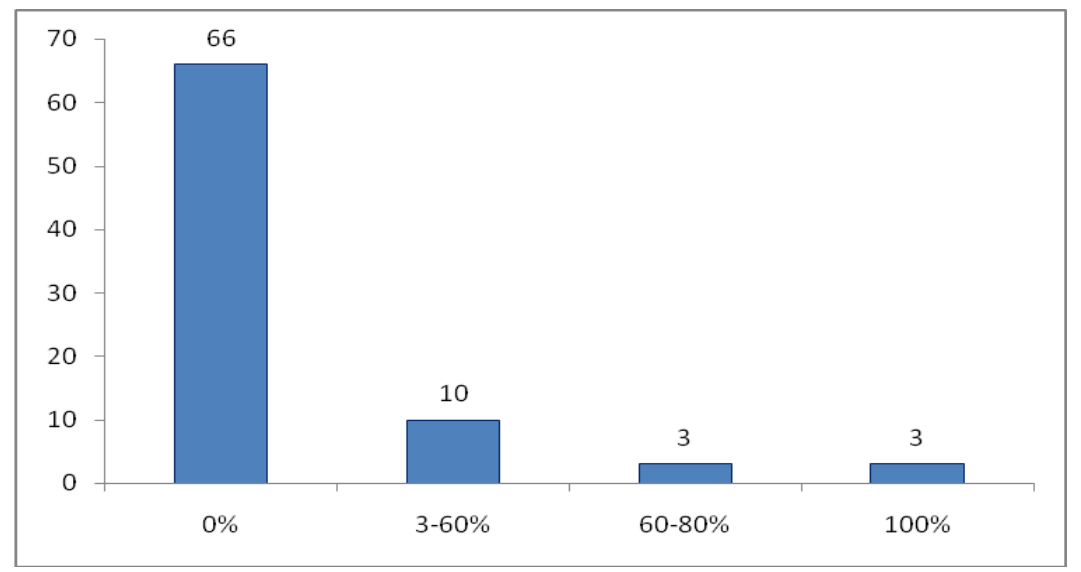

Fig.4 Frequency distribution of selected genotypes for per cent germination under salinity stress $(180 \mathrm{mM} \mathrm{NaCl})$

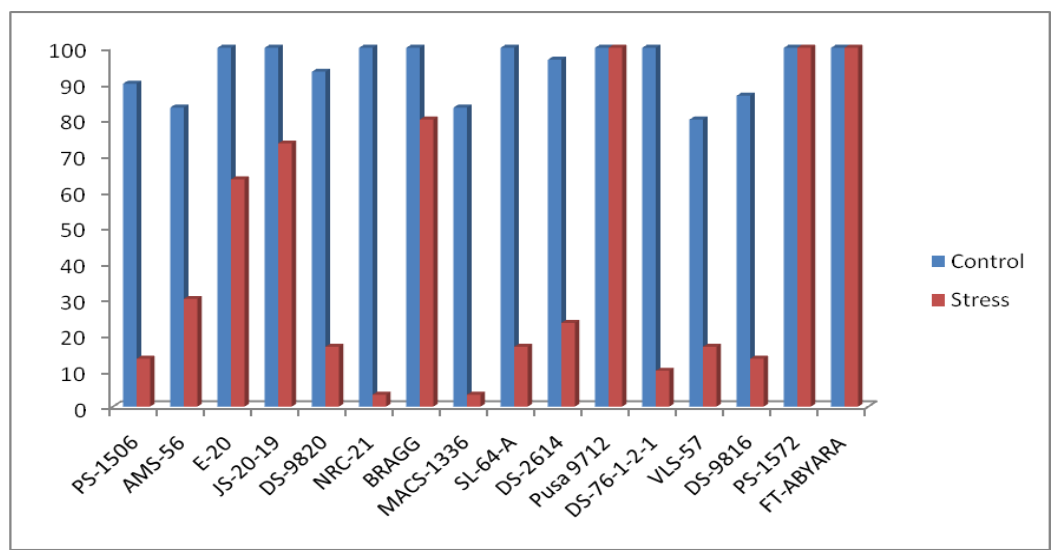


Fig.5 Reduction in root length $(\mathrm{cm})$, shoot length $(\mathrm{cm})$ and percent germination of selected genotypes under salinity stress $(180 \mathrm{mM} \mathrm{NaCl})$

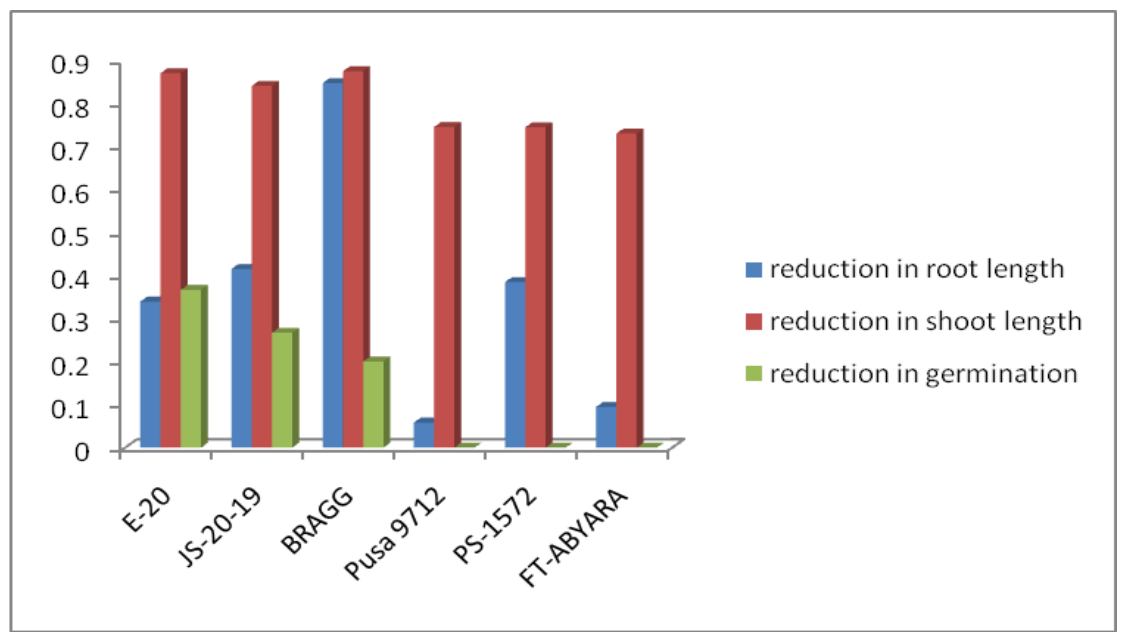

Fig.6 Germination of resistant genotypes (Pusa 9712) (A) and susceptible (B) genotypes (SL958) of soybean under salinity stress
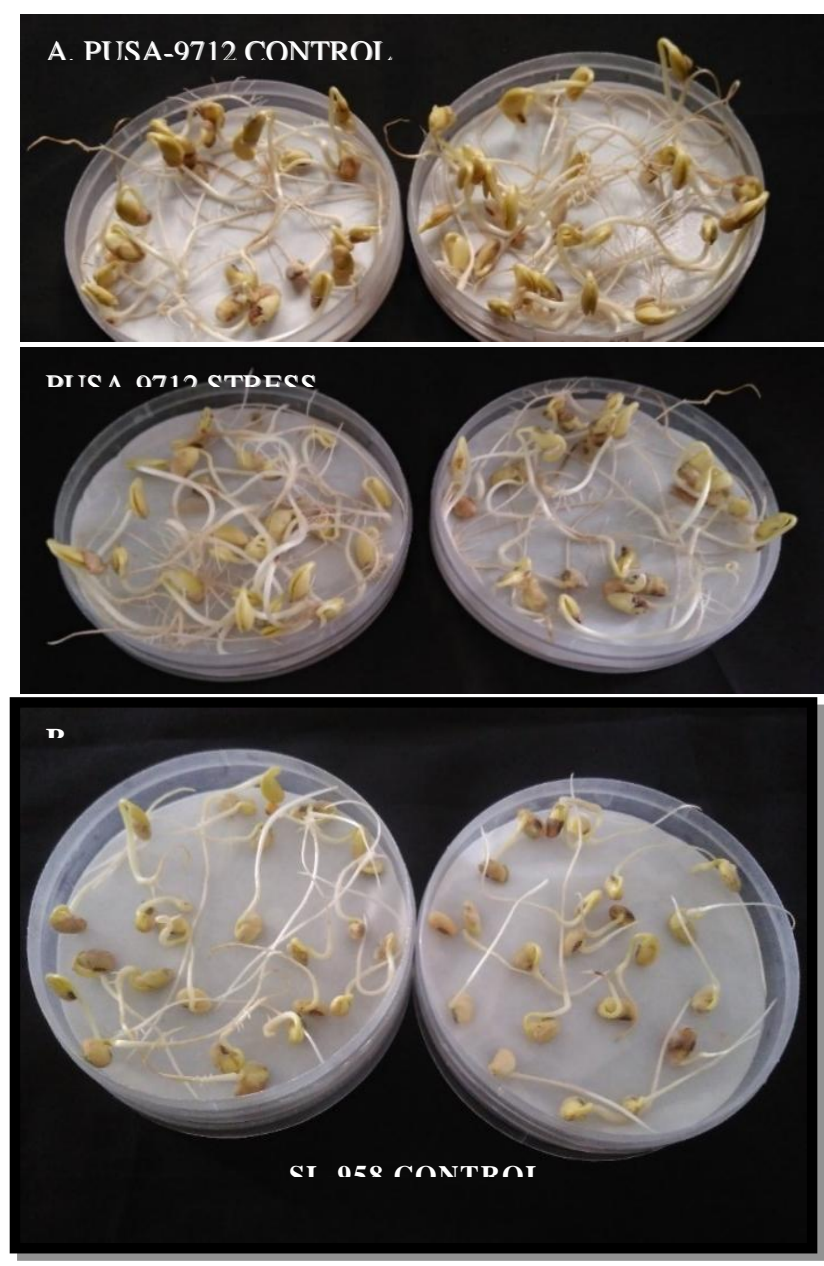

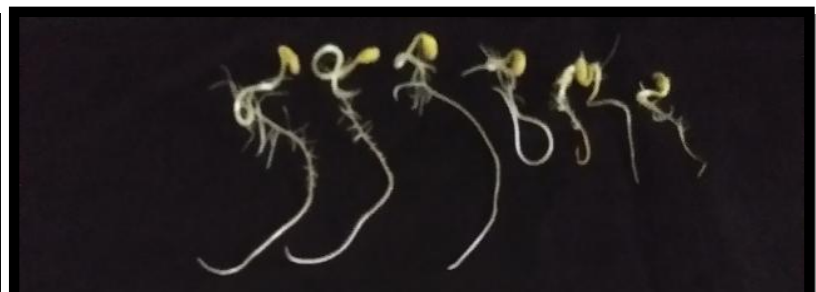

PI ISA-9712 Stress
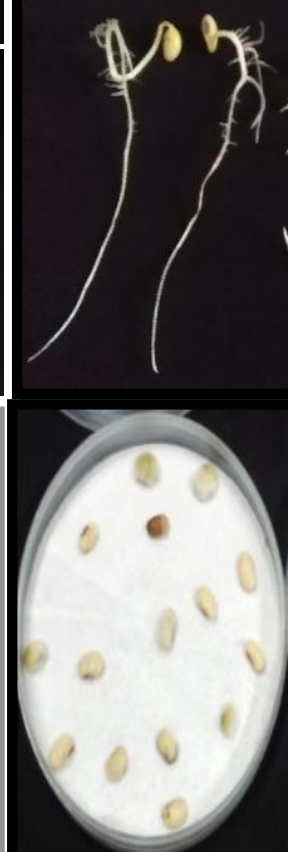
Germination per cent in this experiment represents the number of normal seedlings of each genotype on a certain $\mathrm{NaCl}$ concentration. The germination and germination percentage of control (considering germination in the control as 100 $\%)$ was recorded but it decreased as the salt concentration increased $(180 \mathrm{mM}$ to $250 \mathrm{mM}$ $\mathrm{NaCl})$. Salt affected the process of germination as high salt concentrations decreased the osmotic potential of solution creating a water stress in plants. Reduced germination in saline conditions can be a consequence of either the direct toxic effects of salts or the general delay in the germination process caused by osmotic stress. The germination process has been study in many legumes and crops, and our results lined with germination percentage decreased under the salinity such as, in Vigna (Maliwal and Paliwal, 1982), rice (Gill and Singh, 1985) and wheat (Goudarzi and Pakniyat, 2008). The maximum FGP rate at $180 \mathrm{mM}$ concentration was found in Pusa-9712 (100\%), PS-1572 (100\%), and Bragg (80\%) followed by E-20 (73.33\%), JS-20-19 (63.33 $\%)$ and Pusa-16 (50\%)while, rest were salt sensitive germination was completely inhibited at $180 \mathrm{mM}$ concentration.

The results of this study showed that soybean has a varying response to salinity. Each genotype shows specific response to salinity some genotypes can germinate in saline condition but face growth inhibition in the further development stage. Salt-tolerant genotypes have to well germinate and grow vigorously under saline condition.

In conclusion, the stress caused by $\mathrm{NaCl}$ solution had severe effect on germination as well as early growth. Pusa-9712 and PS-1572 appeared more tolerant as compared to E-20, JS-20-19, Bragg and PUSA-16. Pusa 9712 and PS 1572 can be used for transferring resistance against salinity stress $(180 \mathrm{mM}$ $\mathrm{NaCl})$. The rest of the genotype were susceptible to salt stress $(180 \mathrm{mM} \mathrm{NaCl})$.

\section{Acknowledgement}

First author is grateful to Post Graduate School, Indian Agricultural Research Institute (IARI) and Indian Council of Agricultural Research (ICAR) for providing the fellowship during postgraduate study.

\section{Conflict of Interest}

The authors declare that they have no conflict of interest.

\section{References}

Agarwal, N., Kumar A, Agarwal S and Singh A. 2015. Evaluation of soybean (Glycine max (L.) cultivars under salinity stress during early vegetative growth. Intl J CurrMicrobiolApplSci 4(2):123-134.

Do, D.T., Chen H, Hien Vu T T, Hamwieh A, Yamada T, Sato T, Yan Y, Cong H, Shono M, Suenaga K and Xu D. 2016. $\mathrm{Ncl}$ synchronously regulates $\mathrm{Na}^{+}, \mathrm{K}^{+}$ and $\mathrm{Cl}^{-}$in soybean and greatly increases the grain yield in saline field conditions. Scientific Report 6:19147.

Dolatabadian, A., Modarressanavy S A M, Ghanati F. 2011. Effect of salinity on growth, xylem structure and anatomical characteristics of soybean. SciBiol 3:41-45.

Fooland, M.R., and Jones R A. 1991. Genetic analysis of salt tolerance during germination in Lycopersicon. TheorAppl Genet 81:321-326.

Goudarzi, M., and Pakniyat H. 2008. Comparison between salt tolerance of various cultivars of wheat and maize. $\mathrm{J}$ of Applied Sci. 8(12):2300-2305. 
Gill, K.S., and Singh O S. 1985. Effect of salinity on carbohydrate metabolism during paddy (Oryza sativa (L.)) seed germination under salt stress condition. J. Exp. Biol. 23:384-386.

Hosseini, M.K., Powell A and Bingham I J. 2002. Comparison of the seed germination and early seedling growth of soybean in saline conditions. Seed Science Research 12, 65-172.

Hakim, M.A., Juraimi A S, Begum M, Hanafil M M, Ismail M R and Selamat A. 2010. African J of Biotech, 9(13):1911-1918.

Maliwal, G.L., and Paliwal K V. 1982. Salt tolerance of some mungbean (Vigna radiate), urdbean (Vigna mungo) and guar (Cydmoposis tetragonoloba) varieties at germination and early growth stages. Legume fresh, 65:2330.

Munns, R., and Tester, M., 2008. Mechanisms of salinity tolerance. Annu. Rev. Plant Biol. 59:651-681.

Paternak, D., 1987. Salt tolerance and crop production in comprehensive approach. Annu. Rev. Phytopathol 25:271291.

Singleton, P.W., and Bohlool, B.B., 1984. Effect of salinity on nodule formation in soybeans. Plant Physiol. 74:72-76.

Wang, D., and Shannon, M.C., 1999. Emergence and seedling growth of soybean cultivars and maturity group under salinity. Plant and Soil. 214:117-124.

\section{How to cite this article:}

Shanti Kumari, S K. Lal, V. Sreenivasa, Ambika Rajendran, Sunil Kumar Singh, KP. Singh, S.K. Jain and Xu, D. 2019. Screening and Identification of Sources of Salinity Tolerance at Seed Germination Stage in Indian Soybean Genotypes. Int.J.Curr.Microbiol.App.Sci. 8(04): 3006-3013. doi: https://doi.org/10.20546/ijcmas.2019.804.346 